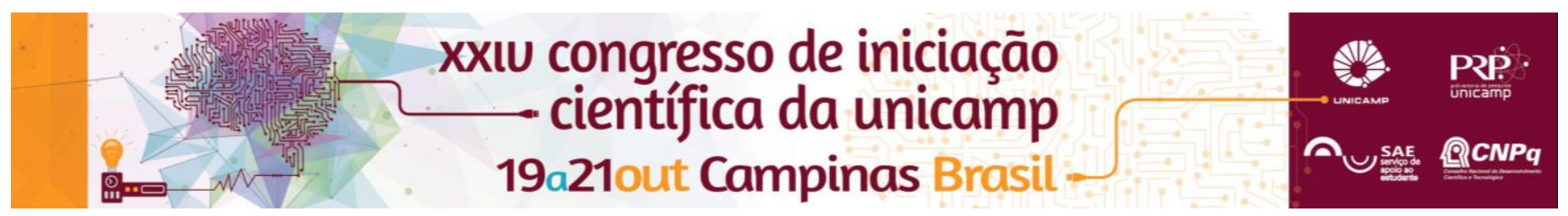

\title{
Estudo da influência da interesterificação enzimática de óleo de buriti na preparação de nanoformulações.
}

\section{Tauan da Silva Narciso Gomes, Gabriela Alves Macedo, Paula Speranza.}

\section{Resumo}

O trabalho visou interesterificar o óleo de buriti com a lipase Lipozyme TL-IM (Novozyme) em 6 e 24 horas de reação, avaliando a distribuição regioespecífica dos ácidos graxos no triacilglicerol. A partir destes óleos, produziu-se nanoemulsões afim de verificar a interferência da interesterificação no tamanho de partícula e no potencial zeta.

\section{Palavras-chave:}

Interesterificação, Óleo de Buriti, Nanoemulsão.

\section{Introdução}

Os óleos quando submetidos a reação de interesterificação enzimática, podem gerar novos óleos com propriedades biológicas superior ao do óleo natural (Speranza et al., 2015). Portanto, o óleo de buriti, que já apresenta muitos compostos com propriedades biológicas, como alta concentração de ácido oleico, tocoferóis e carotenoides, ao se submeter a estas reações, podem gerar um novo óleo com propriedades ainda mais atrativas. A interesterificação é a redistribuição dos ácidos graxos no triacilglicerol, modificando então suas propriedades físico-químicas. Porém, devido a hidrofobicidade e instabilidade dos óleos insaturados, como o de buriti, o mesmo precisa ser encapsulado em carreadores que aumentem a estabilidade e reduzam a sua hidrofobicidade, ampliando assim, o potencial de aplicação do mesmo. Um dos carreadores mais utilizados, as nanoemulsões, apresentam vantagens que incluem segurança toxicológica e fácil produção, sendo largamente utilizadas para fármacos e cosméticos.

Este trabalho teve como objetivo biotransformar o óleo de buriti utilizando diferentes tempos de reação através da enzima comercial Lipozyme TL-IM, caracterizando o óleo quanto a distribuição regioespecífica. Os óleos interesterificados e o óleo natural de buriti foram utilizados para a produção de nanoemulsões, analisando a interferência da biotransformação no tamanho das partículas e no potencial zeta.

\section{Resultados e Discussão}

A reação de interesterificação enzimática foi conduzida em dois tempos diferentes (6 e 24 horas) afim de se verificar o efeito do tempo de reação na estrutura triacilglicerídica do óleo de buriti. Após a interesterificação fez-se a purificação dos óleos para a remoção dos diacilglicerídeos, monoacilglicerídeos, e ácidos graxos livres formados durante a reação. Fez-se então a análise ressonância magnética nuclear (RMN) para se conhecer a distribuição regioespecífica dos óleos. Os resultados podem ser observados na Tabela 1.

Tabela 1. Resultado do RMN dos óleos de buriti bruto e interesterificados de 6 e 24 horas.

\begin{tabular}{|c|c|c|c|}
\hline \multirow{2}{*}{ Óleo } & \multirow{2}{*}{ Posição } & \multicolumn{2}{c|}{ Ácidos Graxos (\%) } \\
\cline { 3 - 4 } & & Saturados & Insaturados \\
\hline \multirow{2}{*}{ Bruto } & $\mathrm{sn} \mathrm{1,3}$ & 35 & 65 \\
\cline { 2 - 4 } & $\mathrm{sn} 2$ & 0 & 100 \\
\hline $\begin{array}{c}\text { Interesterificado } \\
6 \text { horas }\end{array}$ & $\mathrm{sn} \mathrm{1,3}$ & 32 & 68 \\
\cline { 2 - 4 } & $\mathrm{sn} 2$ & 0 & 100 \\
\hline $\begin{array}{c}\text { Interesterificado } \\
24 \text { horas }\end{array}$ & $\mathrm{sn} 1,3$ & 0 & 100 \\
\cline { 2 - 4 } & $\mathrm{sn} 2$ & 0 & 100 \\
\hline
\end{tabular}

Observa-se que a enzima age somente nas posições sn 1,3 , trocando ácidos graxos saturados por insaturados e após 24 horas de reação o óleo se torna totalmente insaturado.

Produziu-se então as nanoemulsões com 10\% $(\mathrm{m} / \mathrm{m})$ da fase lipídica e a fase aquosa composta por $1,2 \%$ de tewwn-80 em água Milli-Q. Ambas foram aquecidas a $85^{\circ} \mathrm{C}$ e pré-emulsionadas para então serem homogeneizadas em dois ciclos de 800 bar e então resfriados a temperatura ambiente. As amostras foram armazenadas a temperatura ambiente $\left(25^{\circ} \mathrm{C}\right)$ e a temperatura de geladeira $\left(5^{\circ} \mathrm{C}\right)$. As nanoemulsões foram avaliadas quanto ao tamanho de partícula e potencial zeta, representados na Tabela 2.

Tabela 2. Resultado do tamanho de partícula e potencial zeta para as nanoemulsões.

\begin{tabular}{|c|c|c|c|c|c|}
\hline \multirow{2}{*}{ Tratamentos } & \multirow{2}{*}{ Período (dias) } & \multicolumn{2}{|c|}{ Tamanho de Partícula } & \multicolumn{2}{|c|}{ Potencial Zeta } \\
\hline & & $5^{\circ} \mathrm{C}(\mathrm{nm})$ & $25^{\circ} \mathrm{C}(\mathrm{nm})$ & $5^{\circ} \mathrm{C}(\mathrm{mV})$ & $25^{\circ} \mathrm{C}(\mathrm{mV})$ \\
\hline \multirow{3}{*}{ Óleo de Buriti } & 1 & $269^{b}$ & $275^{a}$ & $-28,80^{\text {defg }}$ & $-26,20^{b c}$ \\
\hline & 15 & $274^{a}$ & $275^{a}$ & $-30,17^{\mathrm{g}}$ & $-28,50^{\text {cdefg }}$ \\
\hline & 30 & $268^{b}$ & $277^{\mathrm{a}}$ & $-29,30^{\text {efg }}$ & $-29,60^{\mathrm{fg}}$ \\
\hline \multirow{3}{*}{$\begin{array}{c}\text { Óleo } \\
\text { interesterificado } \\
6 \text { horas }\end{array}$} & 1 & $209^{c}$ & $207^{c}$ & $-26,13^{b c}$ & $-25,57^{a b}$ \\
\hline & 15 & $206^{c}$ & $206^{c}$ & $-23,50^{a}$ & $-28,23^{\text {cdefg }}$ \\
\hline & 30 & $206^{c}$ & $206^{c}$ & $-23,97^{\text {bcde }}$ & $-28,60^{\text {cdefg }}$ \\
\hline \multirow{3}{*}{$\begin{array}{c}\text { Óleo } \\
\text { interesterificado } \\
24 \text { horas }\end{array}$} & 1 & $196^{d}$ & $195^{d}$ & $-27,43^{\text {bcdef }}$ & $-28,50^{\text {cdefg }}$ \\
\hline & 15 & $196^{d}$ & $196^{d}$ & $-30,16^{\mathrm{g}}$ & $-30,13^{g}$ \\
\hline & 30 & $206^{c}$ & $195^{d}$ & $-28,43^{\text {cdefg }}$ & $-26,63^{\text {bcd }}$ \\
\hline
\end{tabular}

Legenda: médias com letras iguais não diferem de si a $p<0,05$ pelo teste de Tukey

Pelos dados é possível observar que há diferença significativa no tamanho de partícula entre os diferentes tipos de óleo, sendo que o tamanho de partícula diminui com o tempo de interesterificação. Já nos outros resultados, não é possível observar diferença significativa entre as temperaturas e nem dias de armazenamento, significando que a emulsão não é alterada com o modo de armazenamento nem em até 30 dias.

\section{Conclusões}

Foi possível realizar a interesterificação enzimática do óleo de buriti, obtendo em 24 horas um óleo totalmente insaturado. Também foi possível observar que a interesterificação tem influência no tamanho de partícula, deixando-as menores, provavelmente devido a maior uniformidade do óleo.

\section{Agradecimentos}

Processo $n^{\circ}$ 2015/07503-3, Fundação de Amparo à Pesquisa do Estado de São Paulo (FAPESP).

Speranza, P.; Ribeiro, A. P.; Cunha, R. L.; Macedo, J. A.; Macedo, G. A. Influence of emulsion droplet size on antimicrobial activity of interesterified Amazonian oils. LWT - Food Science and Technology, 2015. 